\title{
$N 92-10761$
}

$\mathrm{SO}_{2}-\mathrm{RICH}$ EQUATORIAL BASINS AND EPEIROGENY OF IO

Alfred S. McEwen, U.S. Geological Survey, Flagstaff, AZ 86001

\section{OBSERVATIONS}

Comparison of Io's large-scale topography (Gaskell et al., 1988 ) with an $\mathrm{SO}_{2}$-abundance map (McEwen et al., 1988) shows that $\mathrm{SO}_{2}$ is concentrated in equatorial topographic basins. In these basins, about 308 of the surface is covered by $\mathrm{SO}_{2}$ at all elevations above the mean triaxial figure, and $\mathrm{SO}_{2}$ coverage increases with decreasing elevation to as much as 568 at elevations below $-1.5 \mathrm{~km}$. The correlation is not good from long $240^{\circ}$ to $360^{\circ}$ where bright areas are covered by red, Pele-type plume fallout, and in the polar regions where the topography is poorly known. The histogram of $\mathrm{SO}_{2}$ abundance binned by elevation appears bimodal, with a secondary concentration of $\mathrm{SO}_{2}$ at high elevations, but it is not certain that this is significant.

Additional observations suggest that the basins have relatively little higher frequency topographic relief. The Loki basin was covered by Voyager high-resolution $(1 \mathrm{~km})$ images; the U.S. Geological Survey map (1987) shows this region to be devoid of large mountains or other rugged topographic features. Tectonic features and aligned volcanoes are concentric to the Loki basin (Schaber et al., 1989). In addition, limb images indicate that the Colchis Regio basin has little relief at scales greater than about $4 \mathrm{~km}$ (MCEwen et al., 1989).

The distributions of active plumes and hotspots show no obvious correlation with the topography. However, the large Peletype plumes (Pele, Surt, and Aten) all erupted from regions higher than the mean figure, and five of the eight Prometheus-type plumes erupted from regions below the mean figure. Pele-type eruptions are more energetic and are associated with high-temperature $(600 \mathrm{~K})$ hotspots, whereas Prometheus-type plumes are long lived and require large volatile $\left(\mathrm{SO}_{2}\right)$ reservoirs (McEwen and Soderblom, 1983). The hotspot distribution shows no clear pattern in relation to the topography, but one cannot rule out their concentration near the margins of basins and swells, similar to the pattern of recent volcanism and enhanced heat flow around the margins of the colorado Plateau (e.g., Keller et al., 1979). However, possible plateau margins are difficult to locate in the Io topographic dataset because of the sparse and irregular datapoint distribution.

\section{MODELS OF HEAT FLOW AND UPLIFT}

The pattern of alternating basins and swells in Io's equatorial region (Gaskell et al., 1988) is similar to the pattern expected if tidal heating in a thin asthenosphere controls the elevation (Segatz et al., 1988). A key question concerning the $\mathrm{SO}_{2}$ /topography relation is whether heat flow increases or decreases with elevation. Gaskell et al. (1988) proposed that broad uplifts are due to increased heat flow and lithospheric thinning, as has been documented and modeled for broad uplifts on Earth, both 
oceanic and continental (Crough and Thompson, 1976; Morgan, 1983; many others). Gaskell et al. applied a simple lithospheric thinning model (from Morgan and Phillips, 1983) to Io and showed that epeirogenic movements of $\pm 1 \mathrm{~km}$ could be explained. This model includes only a lithosphere and asthenosphere, with no differentiated crust. Inclusion of a crust has little effect on uplift unless thinning progresses into the crust (Morgan, 1983).

Ross et al. (1990) interpreted literally this model simplification (with no crust) and rejected it because of evidence that Io should be differentiated, and because this model did not seem consistent with the polar topography (even though the polar topographic data are poorly constrained). They proposed that the basins correspond to areas of higher heat flow, but they did not explain how increased heat flow could lead to lower elevations. Their model (Fig. 6 cartoon) shows a thick "differentiated lithosphere" (i.e., crust with no thermal lithosphere) under topographic highs with a large embayment into the underlying asthenosphere, and a thin lithosphere in topographic lows with an embayment of asthenosphere into the lithosphere. Why would there be a thicker crust over areas of lower asthenospheric heat production? The opposite relation is expected, because the increased magmatic differentiation should thicken the crust over areas of higher asthenospheric heat production. Furthermore, magma production and rise is expected to result in warming and thinning of the lithosphere (or crust), resulting in epeirogenic uplift. If Io's long-wavelength topographic pattern is related to asthenospheric tidal dissipation, then the cause-and-effect relation must be that the pattern of tidal heat production determines the topography. The model of Ross et al. suggests that any correspondence between topography and asthenospheric heat flow is coincidental, thus negating their conclusions about asthenospheric versus mantle tidal heating rates.

\section{WHY IS THE $\mathrm{SO}_{2}$ CONCBNTRATED IN BASINS?}

Cold trapping probably concentrates $\mathrm{SO}_{2}$ frost in optically thick patches (cf. McEwen et al., 1988). There must be some initial mechanism to produce brighter (and colder) surfaces before cold trapping is effective. To preferentially concentrate $\mathrm{SO}_{2}$ in the basins, either the cold traps are preferentially initiated in the basins or frost deposits are preferentially removed from the highlands (or both).

The behavior of sulfur flows suggests one possible mechanism for initiating cold traps in basins. Sulfur lava flows may cover extensive lowland areas on Io (e.g., the basin west of Pele; see Schaber et al., 1989). As sulfur flows cool and age in near-vacuum conditions they become bright white (Nash, 1987), thus initiating cold traps for atmospheric/volcanic $\mathrm{SO}_{2}$.

Alternatively (or additionally), $\mathrm{SO}_{2}$ may be concentrated in basins because the frost deposits are removed or buried more frequently in the highland regions. Io's $\mathrm{SO}_{2}$ is probably delivered to the surface via volcanic outgassing, so we might expect to see 
greater concentrations of $\mathrm{SO}_{2}$ near volcanically active areas. However, the increased heat flow associated with active volcanism might also serve to volatilize and remove surface $\mathrm{SO}_{2}$, or the $\mathrm{SO}_{2}$ could be buried by other volcanic deposits. The result could be that we see $\mathrm{SO}_{2}$ everywhere, but it is patchy and transient in the more volcanically active, topographically elevated regions, whereas cold traps in the basins are long lived so the $\mathrm{SO}_{2}$ becomes optically thick and extensive. Perhaps the secondary $\mathrm{SO}_{2}$ concentration at high elevations is due to volcanic outgassing.

\section{REFERENCES}

Crough, S. T., and Thompson, G. A., 1976, Numerical and approximate solutions for lithospheric thickening and thinning. Earth Plan. Sci. Lett. 31, 397-402.

Gaskell, R. W., Synnott, S. P., McEwen, A. S., and Schaber, G. G., 1988, Large-scale topography of Io: Implications for internal structure and heat transfer. J. Geophys. Res. 15, 581-584.

Keller, G. R., Braile, L. W., and Morgan, P., 1979, Crustal structure, geophysical models, and contemporary tectonism of the Colorado Plateau. Tectonophysics 61, 131-147.

McEwen, A. S., Johnson, T. V., Matson, D. L., and Soderblom, L. A., 1988, The global distribution, abundance, and stability of $\mathrm{SO}_{2}$ on Io. Icarus $75,450-478$.

McEwen, A. S., Lunine, J. I., and Carr, M. H., 1989, Dynamic geophysics of Io. In Belton, M. J. S., West, R. A., and Rahe, J., eds., Time-Variable Phenomena in the Jovian System, NASA $\mathrm{SP}-4994,11-46$.

McEwen, A. S., and Soderblom, L. A., 1983, Two classes of volcanic plumes on Io. Icarus $55,191-217$.

Morgan, P., 1983, Constraints on rift thermal processes from heat flow and uplift. Tectonophysics 94, 277-298.

Morgan, P., and Phillips, R. J., 1983, Hot spot heat transfer: Its application to Venus and implications to Venus and Earth. J. Geophys. Res. 88, 8305-8317.

Nash, D. B., 1987, Sulfur in vacuum: Sublimation effects on frozen melts, and applications to Io's surface and torus. Icarus 72, $1-34$.

Ross, M. N., Schubert, G., Spohn; T., and Gaskell, R. W., 1990, Internal structure of Io and the global distribution of its topography. Icarus 85, 309-325.

Schaber, G. G., Scott, D. H., and Greeley. R., 1989, Geologic map of the Ruwa Patera quadrangle of Io (Ji2). USGS Misc. Inv. Ser. Map I-1980, scale 1:5,000,000.

Segatz, M., Spohn, T., Ross, M., and Schubert, G., 1988, Tidal dissipation, surface heat flow, and figure of viscoelastic models of Io. Icarus 75, 187-206.

U.S. Geological Survey, 1987, Shaded relief map of Io. USGS Misc. Inv. Ser. Map I-1713, scale 1:15,000,000. 